\title{
MAPEAMENTO DIGITAL DE FORMAS DE RELEVO NO AMBIENTE COSTEIRO DO PARANÁ
}

Taísa Comerlato

Universidade Federal do Paraná, Departamento de Geografia taisageo@gmail.com

Marcelo Renato Lamour

Universidade Federal do Paraná, Centro de Estudos do Mar mlamour@ufpr.br

\author{
Claudinei Taborda da Silveira
}

Universidade Federal do Paraná, Departamento de Geografia claudineits@ufpr.br

\begin{abstract}
RESUMO
As formas de relevo das regiões costeiras frequentemente representam um desafio aos métodos de mapeamento geomorfológico, principalmente pela suavidade das feições topográficas. Assim, o objetivo deste trabalho foi realizar o mapeamento digital das formas de relevo nesse ambiente, com o uso combinado da geomorfometria e técnicas de processamento digital de imagem. A área de estudo localiza-se na região do litotal Sul do Paraná, com abrangência na baia de Guaratuba e seu entorno, onde ocorrem extensas planícies costeiras associadas as encostas da Serra do Mar. A análise utilizou uma composição entre o Mapeamento Digital do Relevo, apoiado nas análises dos atributos geomorfométricos derivados de um Modelo Digital de Terreno, e do Processamento Digital de Imagem, pela análise das diferenças espectrais dos níveis de umidade da vegetação. Desta forma, foi possível a identificação de diversas formas de relevo (Morros, Planícies, Terraços, Rampas, etc.) em uma escala 1:25.000. Portanto, o resultado mais significativo deste trabalho foi um novo método semi-automatizado de mapeamento geomorfológico, eficaz (98\%) em identificar feições de amplitudes topográficas distintas.
\end{abstract}

Palavras-chave: Geomorfologia costeira. Baía de Guaratuba/PR. Processamento Digital de Imagens. Geomorfometria.

\section{DIGITAL MAPPING OF RELIEF FORMS IN THE COASTAL ENVIRONMENT OF PARANÁ}

\begin{abstract}
The relief forms of the coastal regions frequently present a challenge to the geomorphological mapping methods, mainly due to the gentle topographic features. Thus, the digital mapping was carried out in a coastal area located on the coast of Paraná, where extensive coastal plains are associated with the Serra do Mar range. The analysis used a composition between Relief Digital Mapping, supported by the analysis of the geomorphometric attributes derived from a Digital Terrain Model, and Digital Image Processing, by analyzing the spectral differences of the vegetation humidity levels. In this way it was possible to identify several forms of relief (Hills, Plains, Terraces, Ramps, etc.) on a $1: 25,000$ scale. Therefore, the most significant result of this work was a new semiautomated method of geomorphological mapping, effective (98\%) in identifying features of different topographic amplitudes.
\end{abstract}

Keywords: Coastal Geomorphology. Bay of Guaratuba. Digital Image Processing. Geomorphometry.

\section{INTRODUÇÃO}

A Zona Costeira no Brasil é constituída por vários ecossistemas e recursos naturais (renováveis ou não), existentes na faixa continental, transicional e marinha (SOUZA et al., 2009). A margem continental sul-sudeste apresenta efeitos do tectonismo Cenozóico, pela atuação de falhamentos

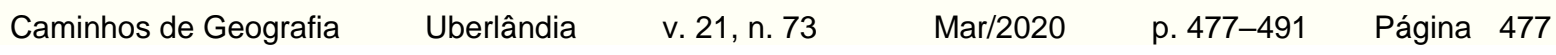


normais com rejeitos verticais ao longo de linhas de fraqueza pré-cambrianas, dando lugar ao deslizamento gravitacional de blocos, os quais se expressam por escarpas de linha de falha, tais como as montanhas que formam a Serra do Mar (ALMEIDA, 1976; ASMUS e FERRARI, 1978). Por sua vez, a Planície Costeira adjacente foi formada pelas oscilações do nível relativo do mar e pela intensa sedimentação ao longo do Período Quaternário (ANGULO, 2004), que distribuíram a ação dos agentes oceanográficos desde o sopé das montanhas até a linha de costa atual.

Os ambientes sedimentares de transição continente-oceano apresentam diversas peculiaridades geomorfológicas, sobretudo pela coexistência de diferentes agentes modificadores naturais e antrópicos do relevo, que agem em escalas espaço-temporais diferentes. Assim, a configuração suavizada do relevo de planície destas regiões trazem dificuldades na detecção das características morfológicas, tanto pelas pequenas amplitudes das feições, quanto pela limitação das escalas cartográficas das bases de dados disponíveis, que muitas vezes são inapropriadas para uma representação eficiente. Frequentemente as cartas temáticas que apresentam as formas de relevo destas regiões utilizam como critério limitador, as formações vegetacionais (mangues e restingas) e/ou formações geológicas (cordões litorâneos e campos de dunas), no intuito principal da resolução das incertezas, o que resulta em maior dificuldade na interpretação dos produtos cartográficos.

Atualmente um dos métodos utilizados para apoiar trabalhos de mapeamento geomorfológico é o emprego de variáveis geomorfométricas obtidas de Modelos Digitais do Terreno, tais como: altitude, declividade, aspecto, diferentes curvaturas, área de contribuição, índice topográfico de umidade, etc. (McBRATNEY et al., 2003; SILVEIRA et al., 2013). Outra abordagem com potencial emprego na cartografia do relevo é a analise da resposta espectral de sensores orbitais, com uso de Processamento Digital de Imagem (PDI).

A combinação de ambas as técnicas na detecção das formas de relevo em regiões costeiras, dada a suavidade das saliências e reentrâncias do relevo, da complexidade na análise e da escala de representação cartográfica, se apresentam como ferramenta de contribuição à cartografia geomorfológica, devido à sua capacidade de aperfeiçoar o processo de mapeamento com critérios quantitativos previamente estabelecidos (BORTOLINI et al., 2017). Desse modo, o objetivo deste trabalho foi fazer o uso combinado da geomorfometria e técnicas de PDI para o mapeamento semiautomatizado das formas de relevo em uma porção do ambiente costeiro paranaense.

\section{ÁREA DE ESTUDO}

O litoral do Paraná apresenta dois sistemas estuarinos dispostos no ambiente costeiro (Baía de Guaratuba e o Complexo Estuarino de Paranaguá), ilhas rochosas distribuídas na plataforma continental rasa (Currais e Itacolomis), e sedimentares nas desembocaduras estuarinas (Peças, Superagui e do Mel). A geologia regional é composta por rochas do Embasamento Cristalino (Período Arqueano-Proterozóico Inferior - Gnaisses, Migmatitos e Granitos) (MINEROPAR, 2006), as quais afloram na forma de elevações topográficas isoladas e ilhas. Segundo Angulo et al. (2006), os segmentos de planície costeira estendem-se desde o sopé da Serra do Mar até o oceano $(55 \mathrm{~km})$, sendo constituídos por depósitos sedimentares continentais associados às encostas (leques, tálus, colúvios e sedimentos fluviais) e costeiros (planície costeira com cordões litorâneos e lamas estuarinas).

As características geomorfológicas deste trecho do litoral brasileiro compreendem os domínios morfoestruturais dos depósitos sedimentares e faixa de dobramentos remobilizados. Ocorrem ainda modelados de acumulação marinha e fluviomarinha; região de Colinas Costeiras e das Escarpas e Reversos da Serra do Mar e da Serra do Mar Paranaense, compostos pelos modelados de dissecação homogênea e diferencial (IBGE, 2009). A morfologia dominante no entorno da baia de Guaratuba (Figura 1) é a de vertentes retilíneas, topos alongados e em cristas e vales em "V" fechados e dissecação alta a muito alta. As feições de relevo são típicas de áreas costeiras apresentando Planícies fluviais e aluviais, marinhas, áreas de influência de maré (áreas de inundação), Colinas suaves a onduladas, Rampas coluvionares, Morros e Serras costeiras (SANTOS et al., 2006). 
Figura 1 - Mapa de localização da área de estudos com a disposição das principais feições de relevo do município de Guaratuba (PR). Sobreposição do Modelo de Relevo sombreado sobre a Imagem de satélite do sensor Basemaps - ArcGIS) e indicação dos pontos amostrais dos trabalhos de campo.

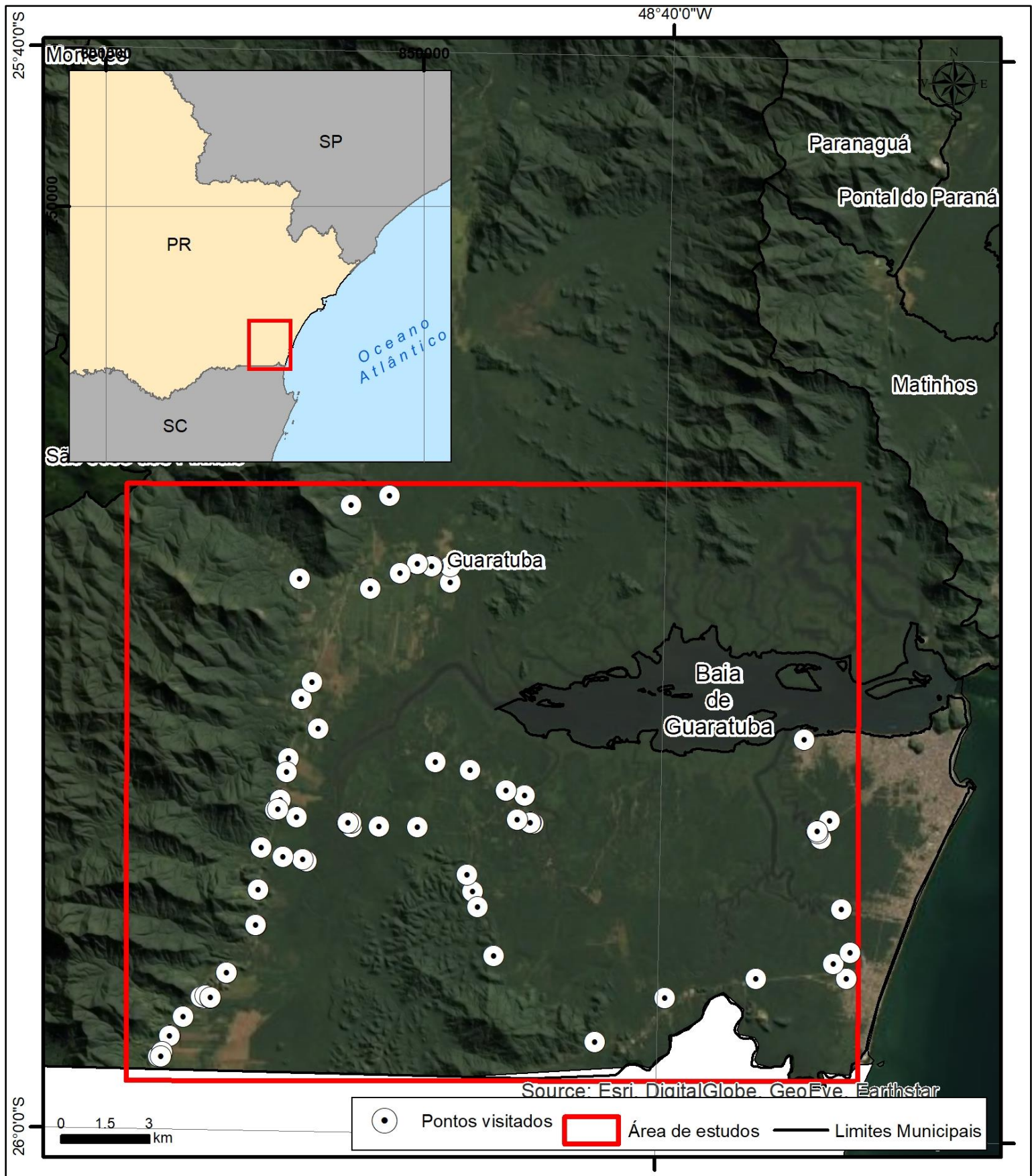

O clima da região é caracterizado como subtropical úmido mesotérmico (Cfa; Köeppen), apresentando verões quentes e pluviosidade média anual elevada $(>2000 \mathrm{~mm})$. Segundo Marone et al. (1995) as maiores intensidades médias dos ventos nessa região procedem dos quadrantes EENE, relacionados às brisas marinhas, e S-SSW relativos à passagem de frentes frias. Sendo que nos meses de verão ocorre a intensificação da circulação da brisa marinha.

O regime de marés junto a linha de costa é semi-diurno (ou seja, duas preamares e duas baixa-mares em um período de 24 horas) com amplitudes de maré de sizígia menores que $2 \mathrm{~m}$, indicando um regime de micro-marés (MARONE et al., 1997). A incidência do trem de ondas é proveniente do quadrante SE (Nemes e Marone, 2013), que geram correntes de deriva longitudinal litorânea

$\begin{array}{lllll}\text { Caminhos de Geografia } & \text { Uberlândia } & \text { v. 21, n. } 73 & \text { Mar/2020 } & \text { p. 477-491 Página } 479\end{array}$


resultante no sentido NE. A área de estudos não se estende até o litoral, pois esta porção encontrase densamente ocupada, dificultando a caracterização geomorfológica pelas técnicas utilizadas. Os dados referentes ao regime de maré são importantes, pois as áreas indentificadas como planícies estuarinas, são diretamente influenciadas por ela.

\section{MATERIAIS E MÉTODOS}

\section{Modelagem Digital do ReleVo}

Parte da abordagem metodológica aplicada neste trabalho trata dos atributos derivados de um Modelo Digital de Terreno (MDT), conhecidos como variáveis morfométricas (SHARY et al., 2002), os quais, aparecem na literatura sob outras designações, como atributos topográficos (MOORE et al., 1991; 1993; WILSON e GALLANT, 2000; CHAGAS, 2006; SILVEIRA et al., 20122013), parâmetros das formas do relevo (SPEIGHT, 1977), variáveis geomorfométricas (BISPO et al., 2009), atributos do terreno (PENNOCK, 2003; CÁTEN et al., 2009), atributos geomorfométricos (SCHMIDT e DIKAU, 1999) e atributos do relevo (IPPOLITI et al., 2005; SIRTOLI et al., 2008).

O MDT foi elaborado tendo como base quatro cartas topográficas digitais (1:25.000, equidistância de $10 \mathrm{~m}$ - folhas 2858-1 NE; 2858-1 SE; 2858-2 NO; e 2858-2 SO) (DSG, 2002) e recortado para a área de estudos, que não seguiu os limites das cartas topográficas e sim o limite da cena da imagem de satélite utilizada (25 km x $25 \mathrm{~km}$ - Figura 1). O MDT foi elaborado com base no interpolador Topogrig, conforme proposta de Hutchinson (1989) adaptada pelo software ArcGIS 9.0 (licença obtida em 2005 pelo Laboratório de Pesquisas Aplicadas em Geomorfologia e Geotecnologia do Departamento de Geografia da Universidade Federal do Paraná. O tamanho do pixel do modelo $(15 \mathrm{~m})$ foi calculado conforme Hengl (2006) que considera duas abordagens: a primeira num viés cartográfico da escala da base de dados e a segunda numa perspectiva das características geomorfológicas locais.

Os critérios que definiram as entidades geomorfológicas (padrões de relevo) foram baseados nos parâmetros de classificação propostos pelo IPT/Emplasa (1990) e complementarmente, por Ponçano et al. (1981) e Ross (1992), a partir da reunião de fatores morfométricos básicos como a amplitude e declividade via álgebra de mapas. Na adaptação dos parâmetros para a área de estudos, o atributo morfométrico declividade foi elaborado com auxilio do software ArcGIS (Slope) para cada célula, quando foi calculada a taxa máxima de alteração no valor para seus vizinhos, levando em consideração a análise de vizinhança em janelas móveis $3 \times 3$. Já a declividade, em valores percentuais, foi calculada pelo software, onde a derivada direcional leste-oeste e a derivada direcional norte-sul na foram calculadas de acordo com o polinômio de Horn (1981).

A amplitude altimétrica é a variável que corresponde à diferença altimétrica entre o nível de base e a maior altitude situada em uma vertente. Ela também é calculada por analise de vizinhança em janelas móveis $3 \times 3$.

O Índice de Posição Topográfica - IPT (WEISS, 2001) é um algoritmo que calcula a diferença entre a elevação de um ponto central $\left(Z_{0}\right)$ e a média da elevação do seu entorno a partir de um raio predeterminado (Z). A análise de vizinhança necessária para a geração deste índice foi realizada por uma janela circular.

A discretização dos valores (WEISS, 2001) foi realizada a partir de testes limiares que puderam representar com eficiência as planícies e terraços fluviais e as planícies aluviais, de acordo com as evidencias de campo e a sobreposição com a rede hidrográfica da base cartográfica (DSG, 2002). O IPT resultante determinou então 2 classes $(10=<-0,5$ e $20=>-0,5)$, as quais foram tomadas como as melhores identificadoras destas feições.

Outro atributo utilizado nesta análise foi o Back Top Hat - BTH (RODRIGUEZ et al., 2002), também considera a análise de vizinhança regional, a partir do MDT. O BTH com função de abertura mensura

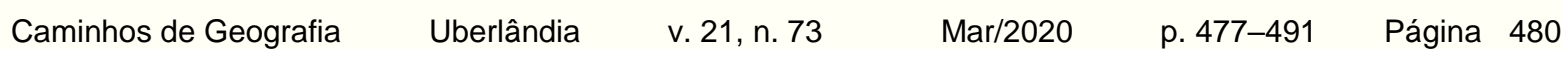


a altimetria mínima da altimetria máxima, que é definido com um raio ou janela prédefinida, e tendo em vista que a proposta original leva em conta que ao subtrair os valores do BTH pelo MDT se obtem a extração dos vales, este modelo foi utilizado para a extração da profundidade do modelo de elevação e na escolha dos parâmetros de análise morfométrica das feições de Planícies e Terraços fluviais e Planícies aluviais (Classe $1=<1,5 \mathrm{~m}$ e Classe $2=>1,5 \mathrm{~m}$ ).

A classificação das áreas planas e baixas foi efetuada pela aplicação dos atributos IPT e BTH, enquanto que 0 atributo morfométrico hipsometria foi obtido a partir da reclassificação do MDT discretizado, e posteriormente reclassificado em duas classes ( $>20 \mathrm{~m} \mathrm{e}<20 \mathrm{~m}$ ), garantindo que áreas de relevo abrupto $(>20 \mathrm{~m}$ ) fossem excluídas da análise. Os raios amostrais dos dois atributos (IPT e BTH) foram diretamente relacionados aos resultados destes modelos, sendo que a alteração destes valores resultou em dados/informações distintas, o que também é valido para os parâmetros de discretização.

A classificação do relevo adaptou os atributos e seus limiares, considerou as formas de relevo (IPT/CPRM, 2014) presentes na área mapeada (planícies e terraços), conforme o BTH e o IPT, os quais foram integrados por geoprocessamento (Raster Calculator). Os valores resultantes da álgebra entre mapas constituíram 3 classes de acordo com os valores dos atributos de origem, o que resultou em uma nova classificação, já com os padrões de formas de relevo (Tabela 1). Estes valores foram determinados tendo em vista que as planícies e terraços fluviais, da área de estudos, não variam mais do que $2 \mathrm{~m}$ entre elas.

Tabela 1 - Parâmetros geomorfométricos utilizados na identificação das áreas planas/baixas.

\begin{tabular}{c|c|c|c}
\hline \multirow{2}{*}{ Forma } & \multicolumn{3}{|c}{ Parâmetros } \\
\cline { 2 - 4 } & IPT & BTH $(\mathrm{m})$ & $\mathrm{ALT}(\mathrm{m})$ \\
\hline 1 - Planícies Fluviais & $<-0,5$ & $<1,5$ & $<20$ \\
\hline 2 - Terraços Fluviais & $<1,5$ & $>-0,5$ & $<20$ \\
\hline 3 - Planícies Aluviais & $>-0,5$ & $<1,5$ & $<20$ \\
\hline 2 - Terraços Fluviais & $>-0,5$ & $>1,5$ & $<20$ \\
\hline
\end{tabular}

O cálculo das variáveis necessárias ao mapeamento das áreas elevadas considerou o comprimento médio das vertentes, mensurados pelo valor médio dos comprimentos dos divisores de água até os fundos de vale. Estas medidas foram realizadas por meio digital a partir das curvas de nível e resultaram em dois tamanhos de raios, um generalizado $(2.000 \mathrm{~m})$ e outro detalhado $(300 \mathrm{~m})$. O raio circular generalizado foi utilizado no cálculo do IPT na modelagem das Serras e Rampas de colúvio enquanto que o raio detalhado para o cálculo da amplitude altimétrica média e a declividade média, considerando-se as duas faces da vertente utilizadas para a modelagem das Colinas, Morrotes e Morros.

Esta distinção entre o tamanho dos raios foi necessária pela disposição geográfica das feições na área mapeada onde elevações topográficas isoladas ocorrem em meio às planícies. Neste caso a modelagem de relevo utilizando um único raio generalizado $(2.000 \mathrm{~m})$ não possibilitou representar estas formas isoladas, como as colinas, por exemplo.

$\mathrm{Na}$ determinação dos limiares dos valores dos atributos morfométricos, que foram utilizados na identificação das formas de relevo, cada atributo foi observado separadamente, tendo como ponto de partida, a análise de formas do relevo que já se tinha a confirmação em campo (Figura 2). Com base nestas análises foram definidos os limiares dos valores dos atributos morfométricos de cada forma de relevo e reaplicado para a área de estudos.

$\begin{array}{llllll}\text { Caminhos de Geografia } & \text { Uberlândia } & \text { v. 21, n. } 73 & \text { Mar/2020 } & \text { p. 477-491 Página } 481\end{array}$


Figura 2 - Determinação dos limiares dos valores dos atributos morfométricos da forma de relevo Morrote.
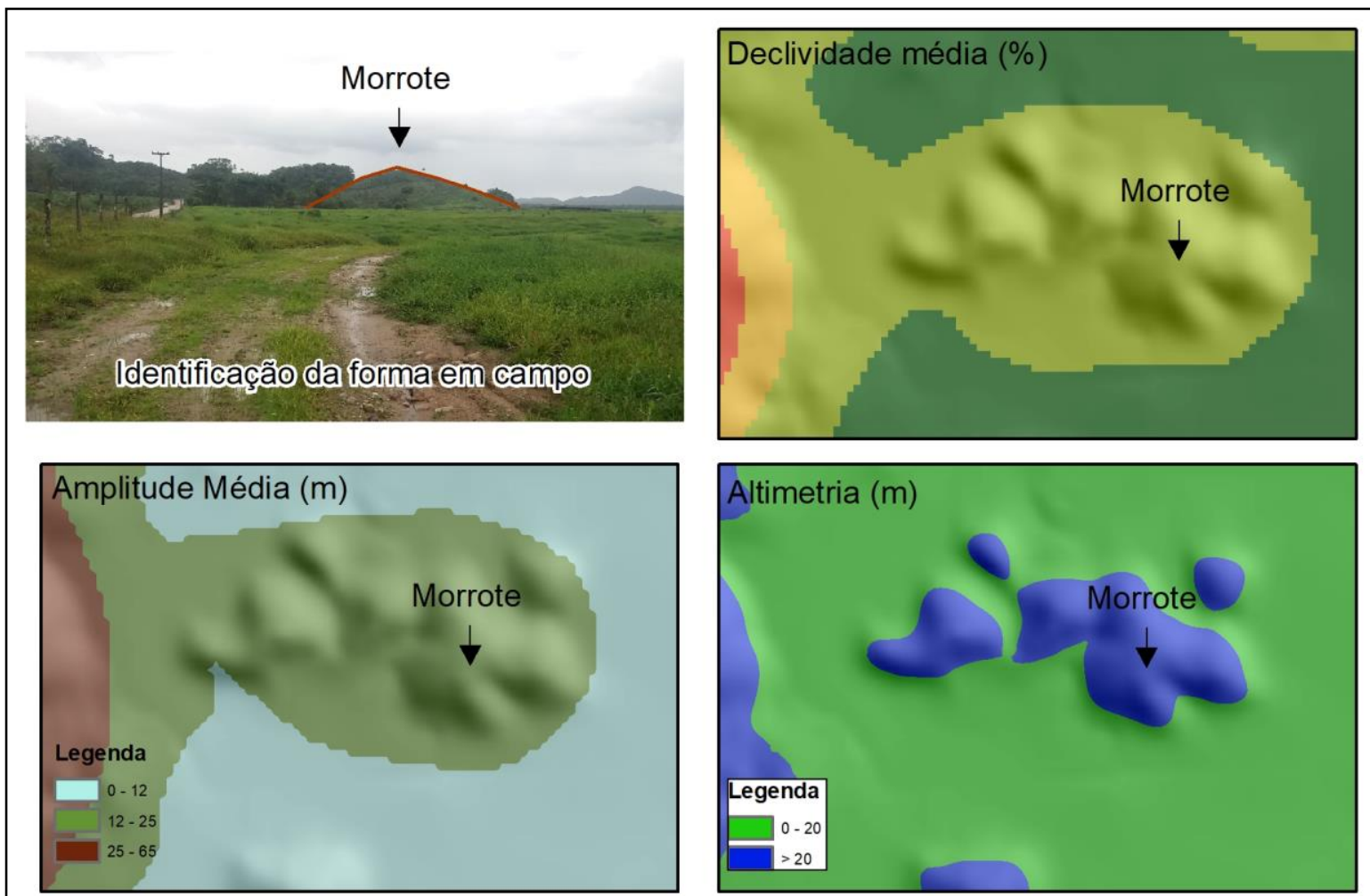

Assinatura Geomorfométrica dos Morrotes: AA $m=12-25 /$ Dec $m=10$ a 25 / Altimetria $=>20$

A análise destes elementos determinou a discretização dos valores geomorfométricos de 5 padrões de formas (Tabela 2).

Tabela 2 - Assinaturas morfométricas das feições elevadas do relevo da área de estudo.

\begin{tabular}{c|c|c|c|c}
\hline Forma & AA $(\mathrm{m})$ & $\begin{array}{c}\text { DEC M } \\
(\%)\end{array}$ & IPT & Altimetria $(\mathrm{m})$ \\
\hline Rampas & $40 \mathrm{a}$ & $5 \mathrm{a} 20$ & IPT detalhado $\leq-1 \mathrm{DP}$ a $<1$ & \\
Coluvionares & 150 & & $\begin{array}{c}\text { DP } \\
\text { IPT generalizado } \leq-1 \mathrm{DP} \text { a }<1 \\
\text { DP e }>5 \text { declividade }\end{array}$ & $>20$ \\
\hline Serras & $>65$ & Qualquer & - & $>20$ \\
\hline Morros & $25-65$ & 25 a 35 & - & $>20$ \\
\hline Morrotes & $12-25$ & 10 a 25 & - & $>20$ \\
\hline Colinas & $0-12$ & 0 a 10 & - & $2014)$
\end{tabular}

Referencias: AA (Amplitude Altimétrica)

DEC M (Declividade Média)

DP (Desvio Padrão)

\section{Processamento Digital de IMAGem}

Os testes de combinação (Composite Bands e Interactive Supervised Classification) das diferentes bandas espectrais $(1 / 2 / 3 ; 1 / 2 / 5 ; 4 / 5$, do sensor RapidEye) determinaram a melhor resposta para cada

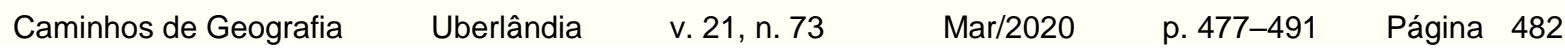


forma de relevo. Este processo identificou o tipo de cobertura vegetal das formas, elencando as áreas de treinamento, como áreas de reconhecimento da assinatura espectral das classes prédeterminadas.

A melhor combinação de bandas para o mapeamento das Planícies e Terraços de deposição estuarina foram as bandas 4 (Red Edge) e 5 (infravermelho próximo), pois a classe Planície está diretamente associada a vegetação de gramíneas, típica de terrenos vegetados por mangues, enquanto que a classe Terraços, pode ser identificada pela textura de vegetação arbustiva. Desta forma, a identificação foi efetuada de forma visual pela diferença do teor de umidade e a textura da cobertura vegetal.

A escolha do método de classificação supervisionada foi realizada pela utilização do Software ArcGIS (Image Classification > Training Sample Manager > Geração do shape das áreas de treinamento > Classify Raster), que demonstrou que o Classificador de Máxima Verossimilhança (Train Maximum Likelihood Classifier) foi o que apresentou melhores resultados na identificação das classes, ou seja, simulou de maneira categórica a diferença no teor de umidade destas feições.

Após a geração das formas por geomorfometria e PDI, foi realizada a álgebra entre mapas agregando ambos os resultados em um único arquivo (

Figura 3). Como o resultado da modelagem digital não detectou as áreas classificadas como Planícies e Terraços estuarinos, nestas áreas, foi realizada a sobreposição do resultado do PDI ao resultado geomorfométrico.

Figura 3 - A) Formas de relevo identificadas por PDI (Classificação Supervisionada). B) Formas de relevo identificadas por geomorfometria. C) Resultado da soma dos dois resultados.

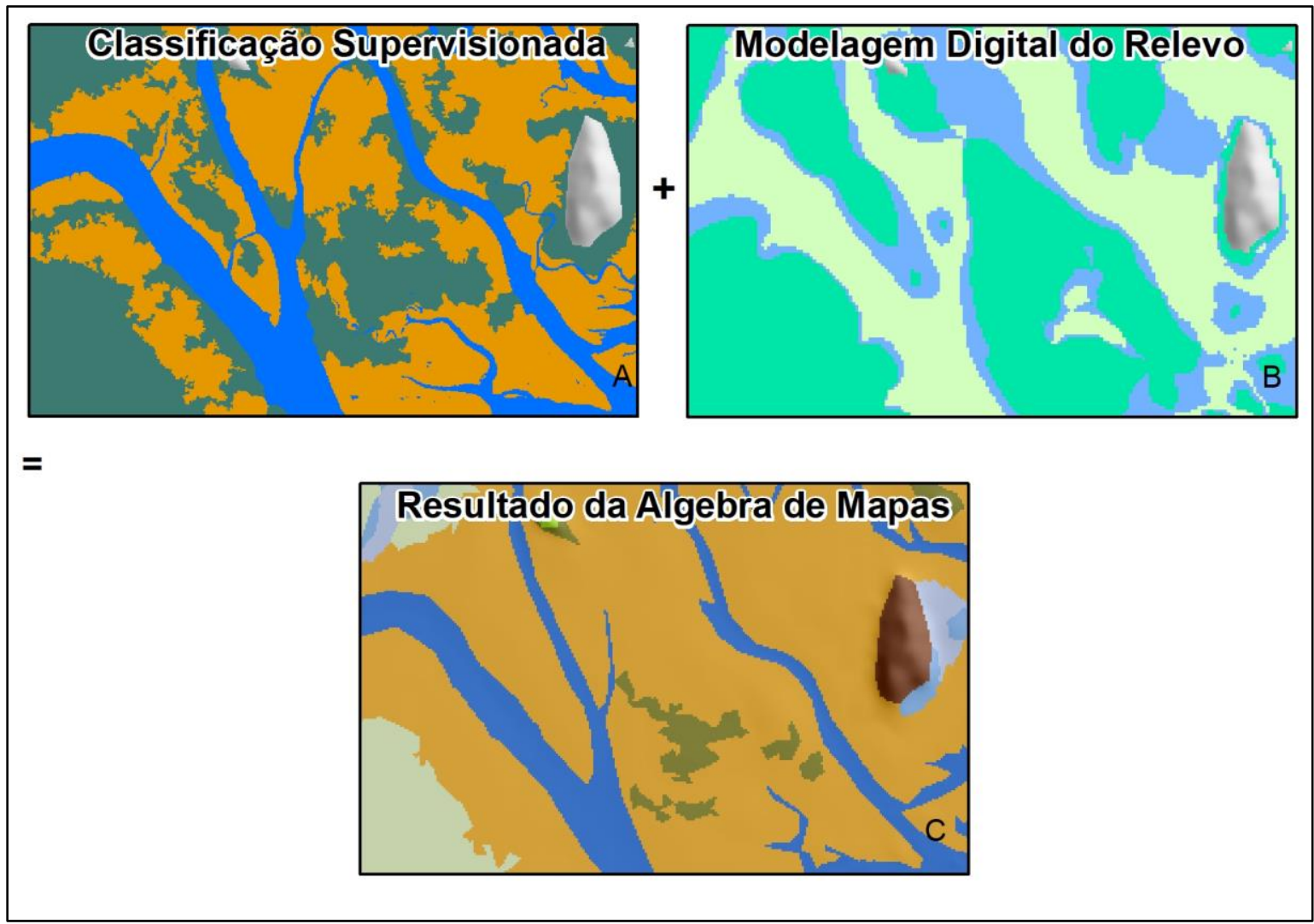


O resultado foi obtido pela operação realizada entre os rasters resultantes da classificação das formas de relevo das áreas planas/baixas (MDR) + formas de relevo das áreas elevadas (MDR) + formas de relevo da área estuarina $(\mathrm{SR})=$ Mapa das formas de relevo da área de estudo.

Ainda, como os rasters de entrada de cada método possuem resoluções espaciais distintas (15 m para o MDT e $5 \mathrm{~m}$ para a imagem de satélite), o resultado do somatório foi reclassificado com resolução espacial de $15 \mathrm{~m}$. E por fim, tendo em vista que a escala final é 1:25.000, de acordo com o conceito de área mínima mapeável $(E=d / D)$ um filtro de generalização foi usado no resultado excluindo polígonos com áreas menores que $25.000 \mathrm{~cm}^{2}$ ou $2,5 \mathrm{~m}^{2}$

Onde: $\mathrm{E}$ = denominador da escala; $\mathrm{d}$ = distância no desenho; $\mathrm{D}=$ distância no terreno.

\section{VALIDAÇÃO DOS RESULTADOS}

A validação das formas concebidas pela modelagem digital e sensoriamento remoto foi realizada pela análise visual das curvas de nível e da imagem de satélite de alta resolução do aplicativo Google Earth (Figura 4) e em campanhas de reconhecimento de campo. Ainda, foram efetuadas análises de gráficos de perfil utilizando a ferramenta 3D Analyst do ArcGIS, onde a amplitude da forma pode ser analisada (Figura 5) ao longo de toda a área mapeada.

Figura 4 - Características utilizadas para a avaliação visual da representação das formas de relevo

(A) de uma porção da área mapeada sobre imagem de satélite (B).

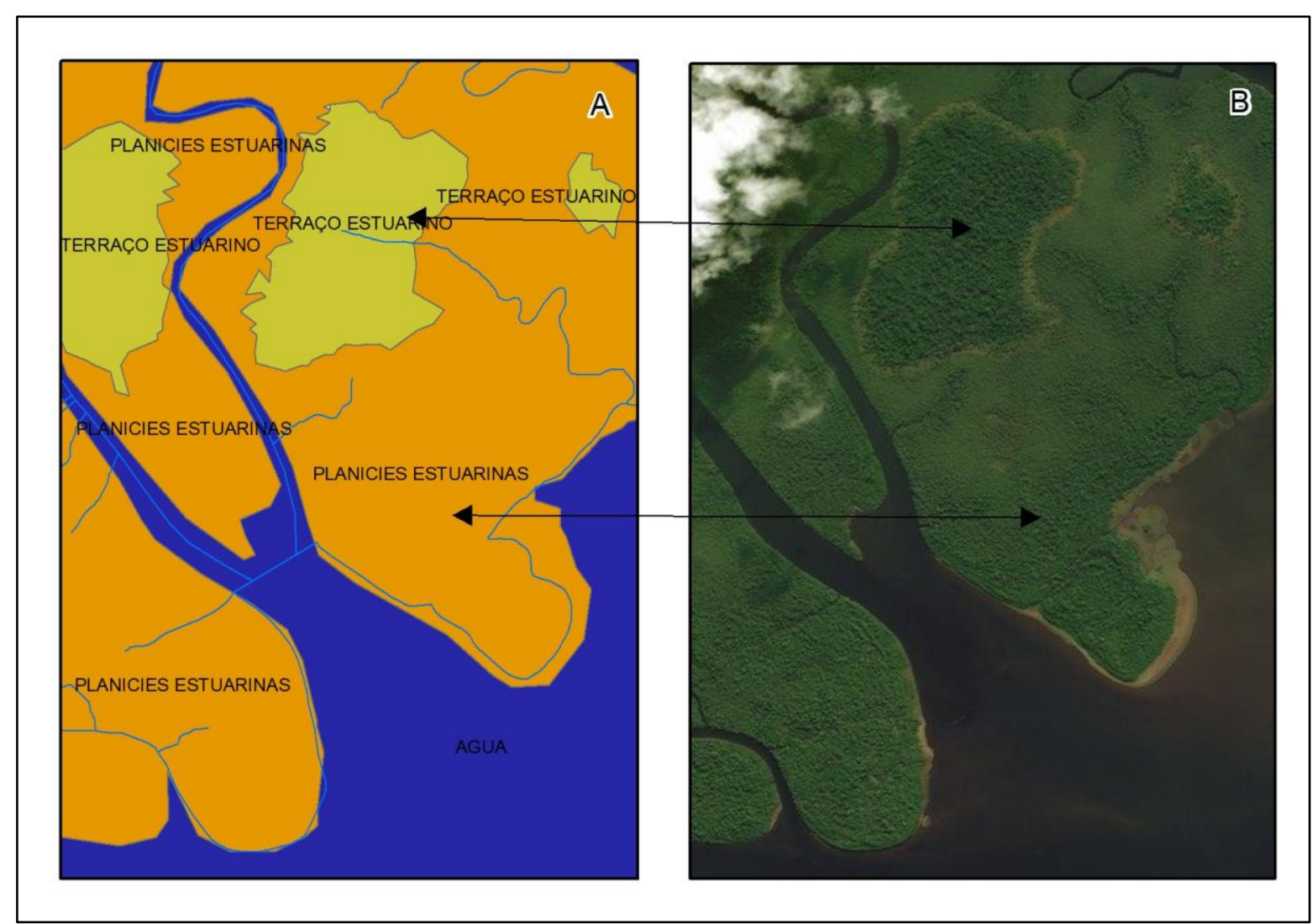

Fonte - Imagem de Satélite do aplicativo Google Earth (2016). 
Figura 5 - Exemplos de gráficos de perfil de uma colina, um morrote e um morro mapeados automaticamente por modelagem digital do relevo.

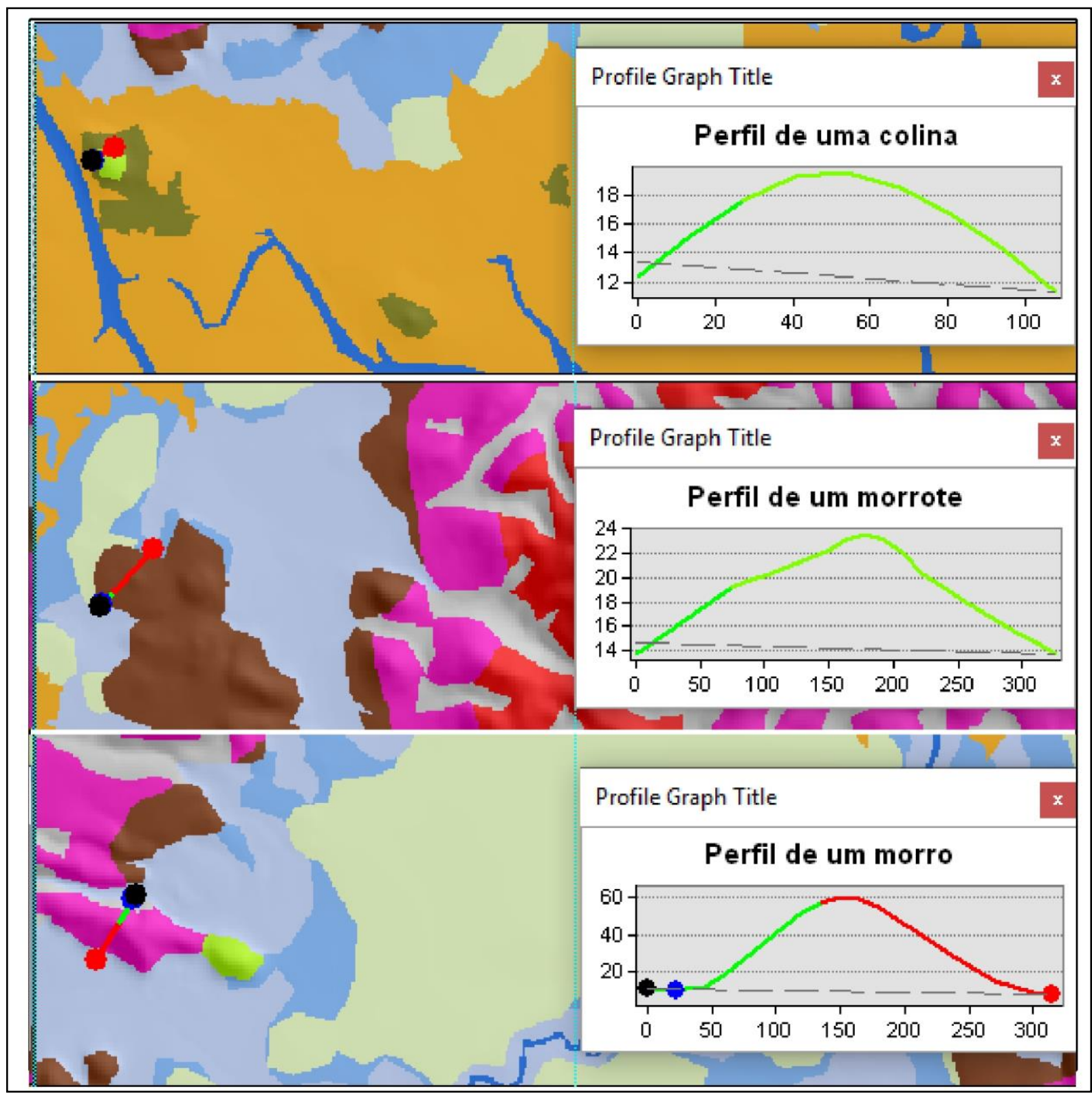

Para a validação de campo foram elencados pontos de conferência preferencialmente onde havia dúvidas sobre o resultado da aplicação dos métodos, bem como, buscando abranger o maior número de amostras de formas de relevo mapeadas. As campanhas resultaram em 98 pontos georreferenciados, apresentados na Figura 1, os quais foram empregados na conferência da qualidade do mapa das formas de relevo.

\section{RESULTADOS E DISCUSSÃO}

O mapeamento dos padrões de formas de relevo da área de estudos revelou onze tipos de formas de relevo (Figura 6), que em mapeamentos anteriores (SANTOS et al., 2006; SILVEIRA e SILVEIRA, $2015 ; 2017)$ não apresentaram tal detalhamento. Tal nível de detalhamento é atribuído a escala do presente trabalho, e pelas técnicas empregadas, sendo que a técnica de PDI foi a que mais contribuiu para distinção das formas, não apresentadas nos trabalhos citados. Assim, a detecção das formas de relevo mostrou-se satisfatória, visto que a porcentagem de acerto dentro do universo dos pontos amostrados nos trabalhos de campo foi de $98 \%$. 
Figura 6 - Mapa de formas de relevo do ambiente litorâneo sobreposto ao modelo de relevo sombreado (Hillshade) - Baia de Guaratuba - PR.

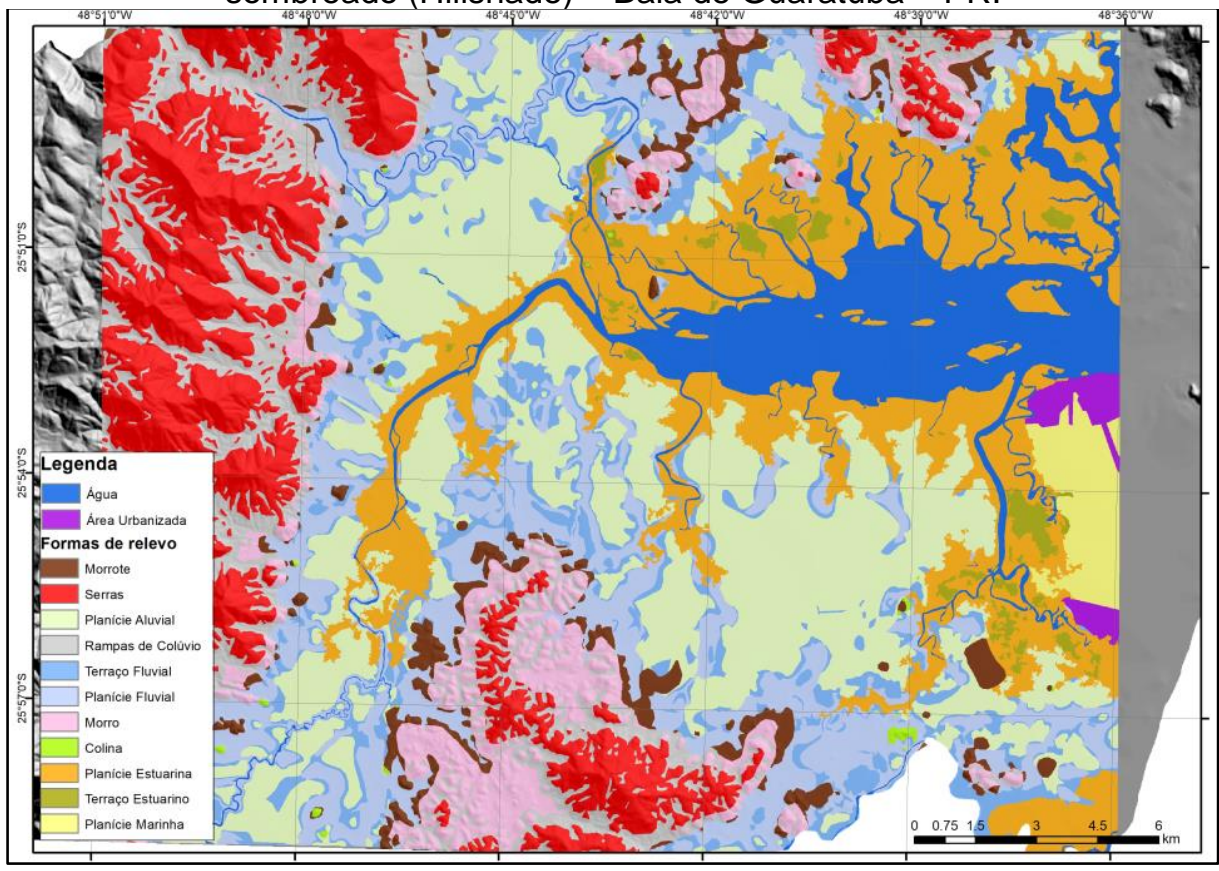

\section{ÁREAS PLANAS/BAIXAS}

O IPT aliado ao BTH apresentou uma combinação de atributos capaz de identificar as formas das Planícies e Terraços fluviais e as Planícies aluviais de forma conclusiva (Figura 7A). As Planícies fluviais representaram áreas baixas do relevo, já as planícies aluviais e terraços fluviais estão em porções um pouco mais elevadas que as planícies fluviais $(1,5 \mathrm{~m})$ a distinção entre elas é dada pela localização dos terraços fluviais, que estão as margens das planícies fluviais.

As campanhas de campo (Figura 7B / 7C), que validaram o mapeamento das feições das áreas planas/baixas evidenciaram que as Planícies aluviais atuais, são áreas ocupadas, em grande parte, para o cultivo agrícola de arroz, o que pode demonstrar baixa salinidade da água subterrânea o que torna o local agricultável, já que a morfologia plana e praticamente sem declividade propicia que estas áreas estejam constantemente alagadas.

Figura 7 - A) Planícies e Terraços fluviais e as Planícies aluviais mapeados pelos atributos BTH e IPT. B) Planícies e Terraços Fluviais. C) Planície Aluvial utilizada para o cultivo de arroz.

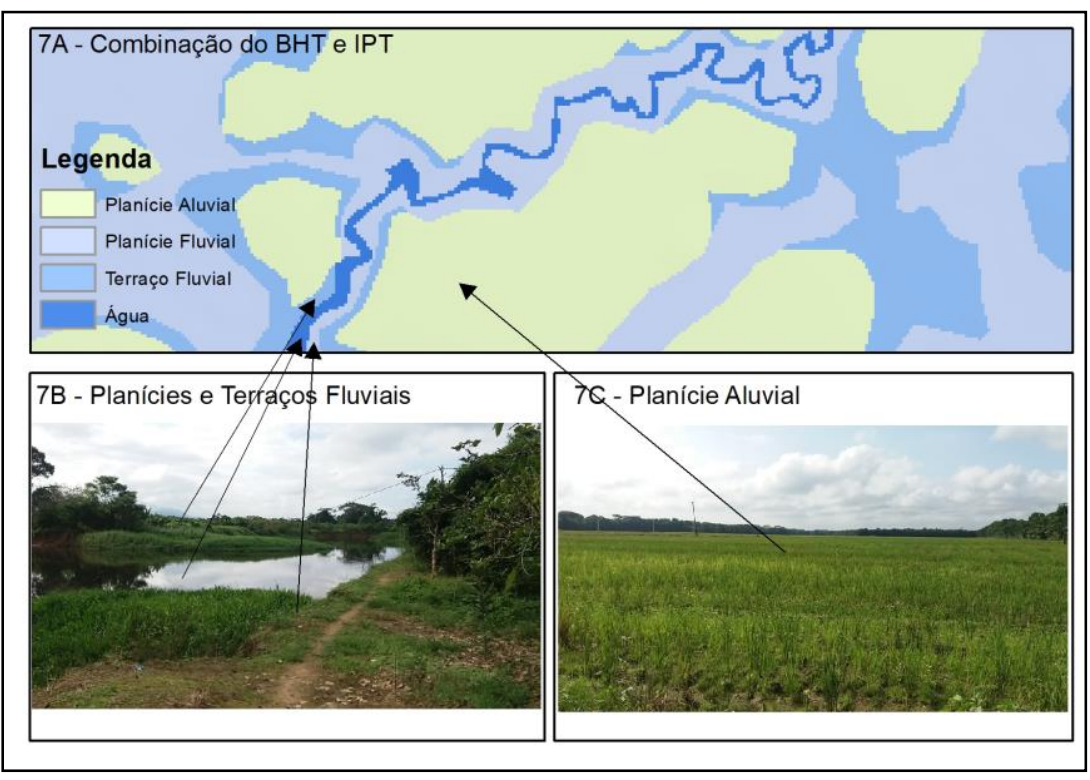


As áreas de influência estuarina, que são representadas pelas Planícies e Terraços de deposição estuarina, que não ficaram bem representadas pela modelagem digital, pois não é possível distinguir seus atributos morfométricos em virtude da restrição da resolução do modelo empregado nas análises. Graças ao uso da técnica de classificação supervisionada de imagem de satélite foi possível a distinção das classes desta porção do ambiente costeiro, confirmadas em campo (Figura 8).

Figura 8 - A) Resultado da classificação supervisionada das classes de Terraços e Planícies. B)

Confirmação do mapeamento da planície estuarina, caracterizada por aparente área úmida e recoberta por vegetação de arbustiva. C) Terraço estuarino recoberto por vegetação arbórea e solo com menos umidade aparente, confirmando o resultado da classificação supervisionada de imagem de satélite.

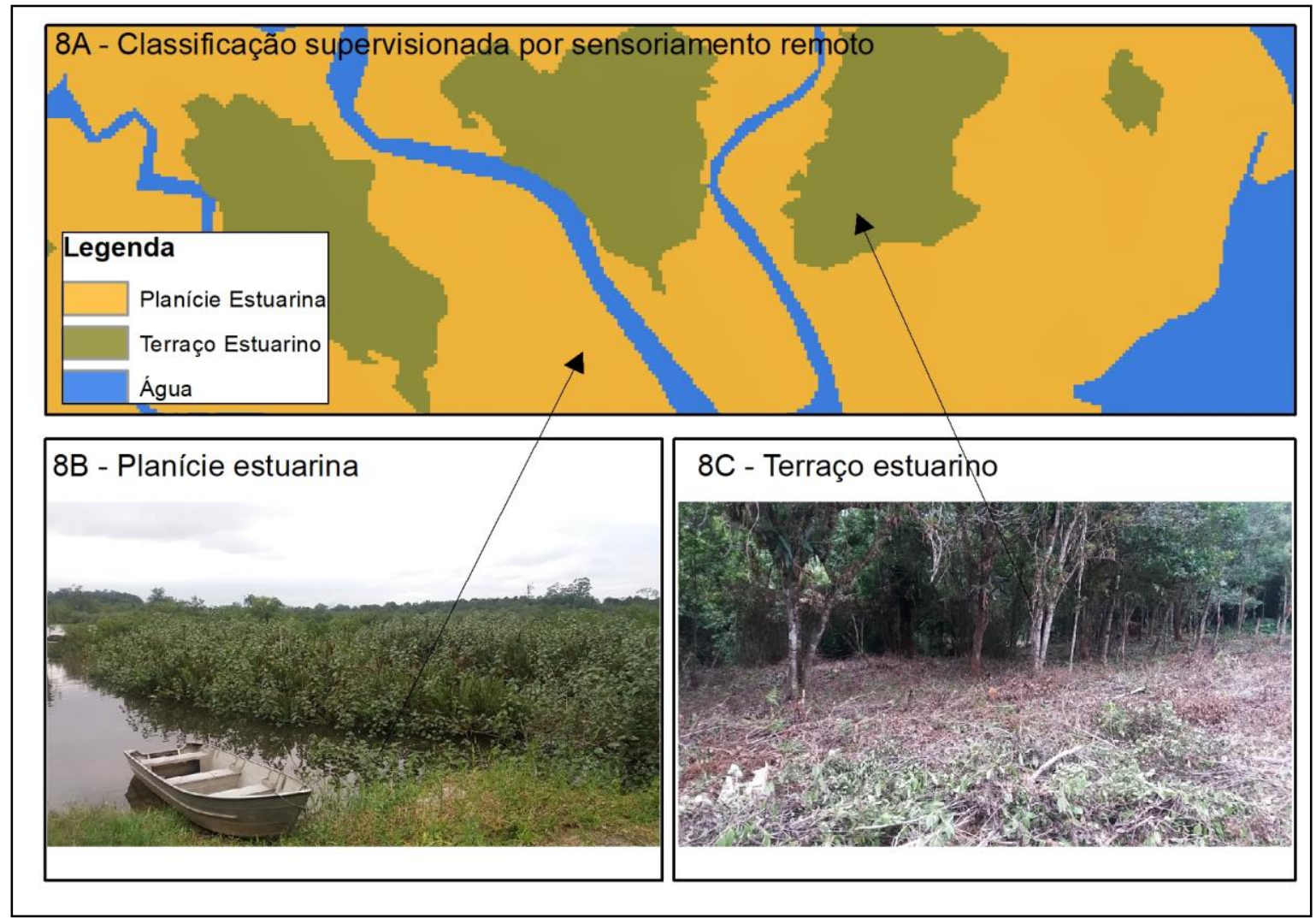

A Planície estuarina é considerada como um ecossistema costeiro de transição entre os ambientes marinhos e terrestres, típico de regiões estuarinas, o qual se encontra em um período submerso e um período emerso (BORGES e SILVA, 2013). Neste sentido, o resultado do mapeamento revela o nível mais alto que a variação da maré atinge nestas porções, confirmado pela diferença de umidade detectado pela banda 4 e 5 do sensor RapidEye. Os Terraços estuarinos são as formas de relevo situadas a poucos metros ou centímetros acima destas planícies, e são identificadas pela diferença de umidade (baixa) das planícies, portanto, são consideradas áreas secas, mas com vegetação capaz de suportar a influência salina (manguezal).

Finalmente a combinação das duas técnicas (PDI e geomorfometria) para as áreas planas e baixas, via álgebra entre mapas, resultou em cinco classes (Planícies e Terraços Fluviais, Planícies Aluviais e Planícies e terraços estuarinos) de formas de relevo. Como a forma de Planície Marinha não pôde ser identificada por nenhuma das técnicas aqui aplicadas, ela foi delimitada manualmente levando em consideração as características geomorfológicas inerentes a esta feição (área com inexpressiva declividade e próxima a orla marinha), pois não foi possível distingui-la das demais formas, já que possuí características morfológicas idênticas às planícies aluviais. 


\section{ÁREAS ELEVADAS}

A combinação dos atributos morfométricos Amplitude altimétrica, Declividade média e IPT resultou na classificação de mais cinco feições (Colinas, Morrotes, Morros, Serras e Rampas coluvionares) de relevo para as áreas elevadas da área de estudos. Porém, somente a combinação destes parâmetros morfométricos aplicados indistintamente para a área não resultou numa boa caracterização das formas de relevo. Isto implicou na aplicação da modelagem digital do relevo utilizando-se tamanhos de raios únicos, o que não proporcionou a representação das feições do relevo inerentes a este ambiente (Colinas e Morrotes). A análise dos tipos de formas avaliando como as mesmas estão dispostas na paisagem foi fundamental para a decisão de utilizar raios distintos para as formas de relevo que se apresentam isoladas na paisagem.

As Colinas do ambiente costeiro possuem características distintas das localizadas em outros compartimentos do relevo, como por exemplo, as do terceiro Planalto, mapeadas por Bortolini et al. (2017) com raio de $750 \mathrm{~m}$. No trabalho destes autores, os atributos topográficos utilizados no mapeamento das colinas foi, igualmente, a amplitude e a declividade média, cuja discretização dos valores seguiu critérios estatísticos e conhecimento prévio de pontos amostrais.

Neste trabalho, quando a modelagem foi realizada com um único raio generalizado as colinas isoladas não apareceram nos resultados. Analisando o resultado preliminar e com o conhecimento de algumas Colinas identificadas em campo, foi possível definir o intervalo dos valores dos atributos amplitude altimétrica e declividade média. Assim, as Colinas foram caracterizadas por vertentes convexo-côncavas, suaves (de 0 \% a 10 \% de declividade) com topos arredondados, localmente rampeadas, com amplitudes altimétrica entre 0 a $20 \mathrm{~m}$.

Os Morrotes, similarmente as Colinas, aparecem na paisagem em meio as planícies aluviais, isoladamente tendo sido mapeados com o mesmo raio aplicado as Colinas (300 m). Esta forma é caracterizada por vertentes convexo-côncavas, declividades entre $10 \%$ a $25 \%$, topos arredondados a angulosos, localmente rampeadas, com amplitude altimétrica entre 20 a $35 \mathrm{~m}$. Além das formas isoladas, os Morrotes aparecem nas bordas dos Morros, isolados ou não.

Os Morros são caracterizados por vertentes convexo-côncavas, declividades que variam de $25 \%$ a $35 \%$, topos angulosos, com amplitude altimétrica entre os 35 e $65 \mathrm{~m}$. Foram mapeados com raio de $300 \mathrm{~m}$, pois são feições que estão bem dissecadas no relevo, em comparação das Serras. A modelagem desta forma foi satisfatória, pois conseguiu distinguir esta das Serras e Morrotes. Sem dúvida, isto se deve a avaliação pontual dos atributos morfométricos onde se tinha o conhecimento prévio da sua localização e reaplicados para o restante da área.

As Serras são caracterizadas por vertentes convexo-côncavas, topos angulosos, com amplitude altimétrica maior que $65 \mathrm{~m}$. Na porção oeste da área, apresentam-se com maior amplitude altimétrica, atingindo mais de $1.500 \mathrm{~m}$ de altitude. Portanto, o raio de análise desta forma, bem como nas Rampas de colúvio foi de $2.000 \mathrm{~m}$. As Rampas de colúvio (tálus) foram identificadas pela disposição espacial comumente no sopé das encostas, com declividades que variaram entre $5 \%$ e $20 \%$ e amplitudes entre 40 e $150 \mathrm{~m}$.

Estas duas feições foram mapeadas utilizando-se o mesmo raio de análise por se entender que as mesmas estão associadas na paisagem. Outra característica distinta das demais formas é que as Rampas de colúvio, além dos atributos de amplitude e declividade médias foi utilizado o IPT, fundamental para garantir que a disposição desta feição estivesse no terço inferior da vertente.

\section{CONCLUSÕES}

O método proposto para o mapeamento de uma pequena porção do ambiente costeiro do Paraná, mostrou-se como uma alternativa viável no mapeamento de formas de relevo em escala de semidetalhe, e pode ser reaplicado em áreas com características semelhantes.

O nível de precisão alcançado de $98 \%$, considerando que foi realizado por técnicas semiautomatizadas, revela que a modelagem digital do relevo, quando utilizada com parâmetros fidedignos à representação morfológica, associada à técnica de classificação supervisionada de imagem de satélite, pode revelar formas de relevo das áreas costeiras, com maior riqueza de detalhes, ainda não detalhados em trabalhos anteriores.

A ausência de detalhes nos mapeamentos geomorfológicos costeiros até hoje executados, não é atribuído a falta de conhecimento de quais são formas de relevo presentes nestas porções, mas sim

$\begin{array}{llllll}\text { Caminhos de Geografia } & \text { Uberlândia } & \text { v. 21, n. 73 } & \text { Mar/2020 } & \text { p. 477-491 } & \text { Página } 488\end{array}$


pela falta de uma metodologia capaz de atender a escalas de detalhe e semi-detalhe, antes só alcançadas por exaustivo trabalho de interpretação visual e trabalhos de campo.

Tal constatação sugere que a pesquisa por técnicas e métodos que facilitem o trabalho de mapeamento geomorfológico é valida sendo que o método ora apresentado pode trazer benefícios tanto quantitativos, pois é capaz de mapear grandes áreas.

Cabe salientar que a mudança nos limiares dos atributos geomorfométricos empregados, bem como do modelo digital do terreno utilizado, podem derivar em resultados diferentes do que os aqui apresentados.

\section{AGRADECIMENTOS}

Os autores agradecem ao Conselho Nacional de Desenvolvimento Científico e Tecnológico (CNPq) pela disponibilização de recursos por meio do Projeto de Mapeamento do Estado do Paraná apoiado em análise digital do relevo e a Coordenação de Aperfeiçoamento de Pessoal de Nível Superior (CAPES) pela disponibilização de bolsa de fomento por meio do Programa de Pós-Graduação em Geografia da Universidade Federal do Paraná (PPGGEO-UFPR).

\section{REFERÊNCIAS}

ALMEIDA, F.F.M. de. The system of continental rifts bordering the Santos Basin, Brazil. Anais da Academia Brasileira de Ciências, v. 48 (supl.), p. 15-26. (Proceedings of the International Symposium on Continental Margins of Atlantic Type, October 1975), 1976.

ANGULO, R. J. Aspectos físicos das dinâmicas de ambientes costeiros, seus usos e conflitos. Desenvolvimento e Meio Ambiente, Curitiba, n. 10, p. 175-185, jul./dez. 2004. https://doi.org/10.5380/dma.v10i0.3107

ANGULO, R. J. et al. Paraná. In: MUEHE, D. (orgs) Erosão e Progradação no Litoral Brasileiro. Brasília: MMA, 2006.

ASMUS, H.E.; FERRARI, A.L. 1978. Hipótese sobre a causa do tectonismo cenozóico na região sudeste do Brasil. In: PETROBRÁS. Aspectos estruturais da margem continental leste e sudeste do Brasil. Rio de Janeiro, PETROBRÁS/CENPES/DINTEP. p.75-88. (Projeto REMAC 4).

BISPO, P. C.; VALERIANO, M. M.; KUPLICH, T. M. Variáveis geomorfométricas locais e sua relação com a vegetação da região do interflúvio Madeira-Purus (AM-RO). Acta Amaz. vol.39 n.1 Manaus Mar. 2009. https://doi.org/10.1590/S0044-59672009000100008

BORGES, A. C. SILVA, V. M. Influência hidrogeoquímica da água subterrânea em manguezais. Geochimica Brasiliensis, Belo Horizonte, 27(2): 98-103, 2013. https://doi.org/10.5327/Z0102$\underline{9800201300020002}$

BORTOLINI, W; SILVEIRA, C. T.; SILVEIRA, R. M. P. Emprego de técnicas geomorfométricas na identificação de padrões de relevo. Revista Ra'e Ga, Curitiba, v. 41 Temático de Geomorfologia, 131150, 2017. https://doi.org/10.5380/raega.v41i0.51724

CÁTEN, A.; DALMOLIN, R. S. D.; RUIZ, L. F. C.; SEBEM, E.; PEREIRA, R. S. Pedometria aplicada à predição de classes de solos utilizando de regressões logísticas múltiplas. In: Simpósio Brasileiro de Sensoriamento Remoto, XIV, 2009, Natal. Anais... Natal: INPE, p. 25-30, 2009.

CHAGAS, C. S. Mapeamento digital de solos por correlação ambiental e redes neurais em uma bacia hidrográfica no domínio de mar de morros. Viçosa, 2006.223p. (Doutorado -Universidade Federal de Viçosa- UFV).

DSG - Diretoria do Serviço Geográfico do Exército Brasileiro. Cartas Topográficas 1:25.000: folhas 2858-1 NE; 2858-1 SE; 2858-2 NO; e 2858-2 SO. DSG, 2002.

GOOGLE. Imagens Google Earth 2016 Disponível em: http://earth.google.com/. Acesso em: 23 de março de 2019.

HENGL, T. Finding the right pixel size. Computers \& Geosciences, 32, Amsterdam: Elsevier, 12831298, 2006. https://doi.org/10.1016/j.cageo.2005.11.008 
HORN, B. K. P. Hill shading and the reflectance map. Proceedings of the IEEE, n. 69, v. 01, p. 14-47, 1981. https://doi.org/10.1109/PROC.1981.11918

HUTCHINSON, M.F. A new procedure for gridding elevation and stream line data with automatic removal of spurious pits. Journal of Hydrology, Amsterdam 106:211-232, 1989. https://doi.org/10.1016/0022-1694(89)90073-5

IBGE - Instituto Brasileiro de Geografia e Estatística. Manual técnico de geomorfologia. Coordenação de Recursos Naturais e Estudos Ambientais. - 2. ed. - Rio de Janeiro: IBGE, 2009. 182 p. - (Manuais técnicos em geociências, ISSN 0103-9598; n. 5).

IPPOLITI, G. A.; COSTA, L.M.; SCHAEFER, C. E.G. R.; FERNANDES FILHO, E. I.; GAGGERO, M. R.; SOUZA, E. Análise digital do terreno: ferramenta na identificação de pedoformas em microbacias na região de "Mar de Morros" (MG). Revista Brasileira de Ciência do Solo, Viçosa, v.29, p.269-276, 2005. https://doi.org/10.1590/S0100-06832005000200012

IPT - Instituto de Pesquisas Tecnológicas do Estado De São Paulo. CPRM - Serviço Geológico do Brasil. Cartas de suscetibilidade a movimentos gravitacionais de massa e inundações, escala 1:25.000 - nota técnica explicativa. São Paulo: IPT/CPRM, 2014

IPT - Instituto de Pesquisas Tecnológicas do Estado De São Paulo. EMPLASA - Empresa Metropolitana de Planejamento da Grande São Paulo -. Carta de aptidão física ao assentamento urbano, escala 1:50.000 - guia de utilização. São Paulo: IPT/ Emplasa, 1990.

MARONE, E; GUIMARÃES, M.R.F.; CAMARGO, R.; PRATA JUNIO, V. P.; KLINGEFUSS, M. S. Caracterização física das condições oceanográficas, meteorológicas e costeiras das zonas estuarinas da Baía de Paranaguá. In: CONGRESSO LATINO - AMERICANO DE CIÊNCIAS DO MAR, 6., Mar del Plata, Argentina. Resumos. p. 129, 1995.

MARONE, E.; MANTOVANELLI, A.; NOERNBERG, M.A.; KLINGENFUSS, M.S.; LAUTERT, L.F.C.; PRATA JUNIOR, V.P. Caracterização física do complexo estuarino de Paranaguá. Pontal do Sul: UFPR. Relatório consolidado do convênio APPA/CEM, 1997.

McBRATNEY, A. B.; MENDONÇA-SANTOS, M. L.; MINASNY, B. On digital soilmapping. Geoderma, Amsterdam, v. 117, n. 1/2, p. 3-52, Nov. 2003. https://doi.org/10.1016/S0016-7061(03)00223-4

MINEROPAR. Atlas geomorfológico do Estado do Paraná: Escala base 1:250.000 modelos reduzidos. Minerais do Paraná; Universidade Federal do Paraná. Curitiba, 2006.

MOORE, I. D.; GESSLER, G.A.; PETERSON, G.A.Soil attribute prediction using terrain analysis.Soil Science Society of America Journal, Madison, Wisconsin, v.57, p.443-452, 1993. https://doi.org/10.2136/sssaj1993.03615995005700020026x

MOORE, I.D., GRAYSON, R.B., LADSON, A. R. Digital terrain modeling: A review of Hydrological, geomorphological an biological applications. Hydrological Processes, Hoboken, New Jersey, v. 5, p. 3-30, 1991. https://doi.org/10.1002/hyp.3360050103

NEMES, D. D.; MARONE, E. Caracterização das ondas de superfície na plataforma interna do litoral do Estado do Paraná, Brasil. Boletim Paranaense de Geociências, Curitiba, v. 68-69, p.12-25. 2013. https://doi.org/10.5380/geo.v69i0.26022

PENNOCK, D. J. Terrain attributes, landform segmentation, and soil redistribution. Soil and Tillage Research, Amsterdam: Elsevier, 69 (1-2), 15-26, 2003. https://doi.org/10.1016/S01671987(02)00125-3

PONÇANO, W. L. (Coord.) et al. Mapa geomorfológico do Estado de São Paulo. São Paulo: IPT, 1981. 2 v. (Publicação IPT, 1 183; Monografias, 5).

RODRIGUEZ, F.; MAIRE, E.; COURJAULT-RAD'E, P.; DARROZES, J. The Black Top Hat function applied to a DEM: a tool to estimate recent incision in a mountainous watershed. (Estibère Watershed, Central Pyrenees). Geophysical Research Letters, Madison, Wisconsin, 29 (6), 9-1 - 9-4, 2002. https://doi.org/10.1029/2001GL014412

ROSS, J. O registro cartográfico dos fatos geomórficos e a questão da taxonomia do relevo. Revista do Departamento de Geografia da USP, São Paulo, n. 06, p. 17-30, 1992. https://doi.org/10.7154/RDG.1992.0006.0002 
SANTOS, L. J. C.; OKA-FIORI, C.; CANALI, N.E.; FIORI, A. P.; SILVEIRA, C. T.; SILVA, J. M. F.; ROSS, J. L. S. Mapeamento geomorfológico do Estado do Paraná. Revista Brasileira de Geomorfologia. São Paulo, v. 7, n.2, p. 3-12, 2006. https://doi.org/10.20502/rbg.v7i2.74

SCHMIDT, J., DIKAU, R. Extracting geomorphometric attributes and objects from digital elevation models - semantics, methods, future needs. In: Dikau, R., Saurer, H. (Eds.), GIS for Earth Surface Systems - Analysis and Modelling of the Natural Environment.Stuttgart: Schweizbart'sche Verlagsbuchhandlung, pp. 153-173, 1999.

SHARY, P.A., SHARAYA, L.S., MITUSOV, A.V. Fundamental quantitative methods of land surface analysis. Geoderma, Amsterdam, 107 (1-2), 1-32, 2002. https://doi.org/10.1016/S00167061(01)00136-7

SILVEIRA, C. T. OKA-FIORI, C.; SANTOS, L. J. C; SIRTOLI, A. E.; SILVA. Pedometria apoiada em atributos topográficos com operações de tabulação cruzada por álgebra de mapas. Revista

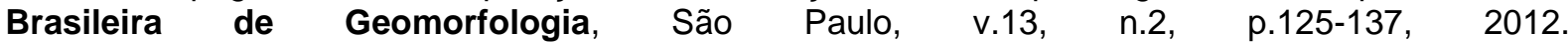
https://doi.org/10.20502/rbg.v13i2.180

SILVEIRA, C. T. OKA-FIORI, C.; SANTOS, L. J. C; SIRTOLI, A. E.; SILVA, C. R.; BOTELHO, M. F. Soilpredictionusing artificial neural networks andtopographicattributes. Revista Geoderma 195196, p. 165-172, 2013. https://doi.org/10.1016/j.geoderma.2012.11.016

SILVEIRA, R. M. P.; SILVEIRA, C. T. Classificação hierárquica automatizada de formas do relevo no estado do Paraná apoiada na modelagem digital do terreno. Revista Brasileira de Geografia Física, Pernambuco, v. 08 n. 05, p. 1509-1523, 2015.

SILVEIRA, R. M. P.; SILVEIRA, C. T. Índice de Posição Topográfica (IPT) para classificação geomorfométrica das formas de relevo no estado do Paraná - Brasil. Revista Ra'e Ga, Curitiba, v. 41 Temático de Geomorfologia, p. 98-130, 2017. https://doi.org/10.5380/raega.v41i0.51674

SIRTOLI, A. E.; SILVEIRA, C. T.; MONTOVANI, L. E.; SIRTOLI, A. R. A.; OKA-FIORI, C. Atributos do relevo derivados de modelo digital de elevação e suas relações com solos. Scientia agraria, Curitiba, v.9, n.3, p.317-329, 2008. https://doi.org/10.5380/rsa.v9i3.11517

SOUZA, K. G. MARTINS, L. R. CAVALCANTI, V. M, PEREIRA, C.V \& BORGES, L.F. Recursos nãovivos da Plataforma Continental Brasileira e Áreas Oceânicas Adjacentes. Gravel. ISSN 16785975. Edição especial, Porto Alegre, 86 p., março 2009.

SPEIGHT, J.G. SpeightLandform pattern description from aerial photographs Photogrammetry, Amsterdam: Elsevier, 32 (1977), pp. 161-182. 1977. https://doi.org/10.1016/0031-8663(77)90012-6

WEISS, A. Topographic Position and Landforms Analysis. Poster presentation, ESRI User Conference, San Diego, CA, 2001.

WILSON, J. P.; GALLANT, J. C. Terrain Analysis: Principles and Applications. New York: John Wiley \& Sons Inc., 2000.

Recebido em: 15/07/2019

Aceito para publicação em: 04/02/2020 